Supplement of Arch. Anim. Breed., 59, 151-157, 2016

http://www.arch-anim-breed.net/59/151/2016/

doi:10.5194/aab-59-151-2016-supplement

(C) Author(s) 2016. CC Attribution 3.0 License.

(c) (i)

Supplement of

\title{
A novel 17 bp indel in the $S M A D 3$ gene alters transcription level, contributing to phenotypic traits in Chinese cattle
}

Tao Shi et al.

Correspondence to: Hong Chen (chenhong1212@263.net)

The copyright of individual parts of the supplement might differ from the CC-BY 3.0 licence. 


\section{Supplementary Material}

Table S1 Primers in bovine SMAD3 for variations detection

\begin{tabular}{|c|c|c|c|c|c|}
\hline $\mathrm{Name}^{\mathrm{a}}$ & $\begin{array}{l}\text { Primer sequences } \\
(5 \text { 'to3') }\end{array}$ & $\begin{array}{l}\text { Position of amplicon } \\
\text { in } \mathrm{NC}_{-} 007308^{\mathrm{b}}\end{array}$ & $\begin{array}{l}\text { Size } \\
(\mathrm{bp})\end{array}$ & $\begin{array}{l}\mathrm{T}_{\mathrm{a}} \\
\left({ }^{\circ} \mathrm{C}\right) \\
\end{array}$ & Location within gene \\
\hline $\mathrm{P} 1$ & $\begin{array}{l}\text { F: CAAAGTTTGGCTGGGGGTTG } \\
\text { R:GAGGTGAAAAGCCAATGCGG }\end{array}$ & nt- 409 to 750 & 847 & 67.3 & $\begin{array}{l}\text { 5'UTR,Exon 1, } \\
\text { partial Intron } 1\end{array}$ \\
\hline $\mathrm{P} 2$ & $\begin{array}{l}\text { F:TCACTGTCCGTTTCTGCTCC } \\
\text { R: GCCTTGCTATTTCCGCTTC }\end{array}$ & nt 100225 to101019 & 795 & 61.4 & $\begin{array}{l}\text { Exon 2,3 and } \\
\text { partial Intron 1, 2, } 3\end{array}$ \\
\hline P3 & $\begin{array}{l}\text { F: CCTTTCGGAGCCATCTAC } \\
\text { R: TCTTCCATCAGGGCATACA }\end{array}$ & nt 101364 to 102434 & 1071 & 57.0 & $\begin{array}{l}\text { Exon } 4 \text { and } \\
\text { partial Intron 3, } 4\end{array}$ \\
\hline P4 & $\begin{array}{l}\text { F:TGCGGGCTTGATTAGACG } \\
\text { R: GCCCACTTGTCAGCCGTA }\end{array}$ & nt 105182 to 106585 & 1404 & 62.5 & $\begin{array}{l}\text { Exon } 5 \text { and } \\
\text { partial Intron 4, } 5\end{array}$ \\
\hline P5 & $\begin{array}{l}\text { F:CTTGAAGATGGCTCTGACCT } \\
\text { R: AAGGGTCTTCCTCTACTGCT }\end{array}$ & nt 114439 to 115116 & 696 & 61.4 & $\begin{array}{l}\text { Exon } 6 \text { and } \\
\text { partial Intron 5, } 6\end{array}$ \\
\hline P6 & $\begin{array}{l}\text { F:GCTGCTAGAGACCAGTCACC } \\
\text { R:TGAGACAGCAAGGCACAGAG }\end{array}$ & nt 117001 to 1177415 & 415 & 61.4 & $\begin{array}{l}\text { Exon } 7 \text { and } \\
\text { partial Intron } 6,7\end{array}$ \\
\hline P7 & $\begin{array}{l}\text { F: CCTCCCTATTGAAGTGGCG } \\
\text { R: ACTGCTGGCATCTCCTCC }\end{array}$ & nt 119469 to 120312 & 861 & 61.4 & $\begin{array}{l}\text { Exon } 8 \text { and } \\
\text { partial Intron } 7,8\end{array}$ \\
\hline P8 & $\begin{array}{l}\text { F: ACCTCCTTTCCCTTCCTG } \\
\text { R: CTCTGGGTTTGCTTTCGT }\end{array}$ & nt 122029 to 122531 & 503 & 57.0 & $\begin{array}{l}\text { Exon } 9 \text { and } \\
\text { partial Intron 8, 9, 3'UTR }\end{array}$ \\
\hline
\end{tabular}

Note: ${ }^{\text {a }}$ P1, P2, P3, P4, P5, P6, P7, P8 were primer pairs for sequencing, covering

all of exons and partial introns of SMAD3 gene.

${ }^{\mathrm{b}}$ Nucleotide +1 is the transcription initiation site; the nucleotide 5 ' to +1 is numbered 